\title{
Modeling the Costs of Trade Finance During the Financial Crisis of 2008-2009: An Application of Dynamic Hierarchical Linear Model
}

\author{
Shantanu Mullick ${ }^{1(\bowtie)}\left(\mathbb{D}\right.$, Ashwin Malshe ${ }^{2}$, and Nicolas Glady ${ }^{3}$ \\ ${ }^{1}$ Eindhoven University of Technology, 5612AZ Eindhoven, The Netherlands \\ s.mullick@tue.nl \\ ${ }^{2}$ University of Texas at San Antonio, San Antonio, TX 78249, USA \\ 3 Telecom Paris, 91120 Palaiseau, France
}

\begin{abstract}
The authors propose a dynamic hierarchical linear model (DHLM) to study the variations in the costs of trade finance over time and across countries in dynamic environments such as the global financial crisis of 2008-2009. The DHLM can cope with challenges that a dynamic environment entails: nonstationarity, parameters changing over time and cross-sectional heterogeneity. The authors employ a DHLM to examine how the effects of four macroeconomic indicators - GDP growth, inflation, trade intensity and stock market capitalization - on trade finance costs varied over a period of five years from 2006 to 2010 across 8 countries. We find that the effect of these macroeconomic indicators varies over time, and most of this variation is present in the year preceding and succeeding the financial crisis. In addition, the trajectory of time-varying effects of GDP growth and inflation support the "flight to quality" hypothesis: cost of trade finance reduces in countries with high GDP growth and low inflation, during the crisis. The authors also note presence of country-specific heterogeneity in some of these effects. The authors propose extensions to the model and discuss its alternative uses in different contexts.
\end{abstract}

Keywords: Trade finance $\cdot$ Financial crisis $\cdot$ Bayesian methods $\cdot$ Time series analysis

\section{Introduction}

Trade finance consists of borrowing using trade credit as collateral and/or the purchase of insurance against the possibility of trade credit defaults [2, 4]. According to some estimates more than $90 \%$ of trade transactions involve some form of credit, insurance, or guarantee [7], making trade finance extremely critical for smooth trades. After the global financial crisis of 2008-2009, the limited availability of international trade finance has emerged as a potential cause for the sharp decline in global trade [4, 13, 21]. ${ }^{1}$ As a result, understanding how trade finance costs varied over the period in and

\footnotetext{
${ }^{1}$ See [27] for counter evidence. 
around the financial crisis has become critical for policymakers to ensure adequate availability of trade finance during crisis periods in order to mitigate the severity of the crisis. $^{2}$ In addition, as the drivers of trade finance may vary across countries, it is important to account for heterogeneity while studying the effect of these drivers on trade finance [20].

A systematic study of the drivers of trade finance costs can be challenging: modeling the effects of these drivers in dynamic environments (e.g., a financial crisis) requires one to have a method that can account for non-stationarity, changes in parameters over time as well as account for cross-sectional heterogeneity [42]. First, nonstationarity is an important issue in time-series analysis of observational data [36, 42]. ${ }^{3}$ The usual approach to address nonstationarity requires filtering the data in the hope of making the time-series mean and covariance stationary. ${ }^{4}$ However, methods for filtering time series, such as first differences can lead to distortion in the spectrum, thereby impacting inferences about the dynamics of the system [22]. Further, filtering the data to make the time-series stationary can (i) hinder model interpretability, and (ii) emphasize noise at the expense of signal [43].

Second, the effect of the drivers of trade finance costs changes over time [10]. These shifts happen due to time-varying technological advances, regulatory changes, and evolution of the banking sector competitive environment, among others. As we are studying 2008-2009 global financial crisis, many drivers of the costs may have different effects during the crisis compared to the pre-crisis period. For example, during the crisis many lenders may prefer borrowers with the top most quality, thus exhibiting a "flight to quality" [12]. To capture changes in model parameters over time, studies typically use either (1) moving windows to provide parameter paths, or (2) perform a before-and-after analysis. However, both these methods suffer from certain deficiencies. Models that yield parameter paths $[11,32]$ by using moving windows to compute changes in parameters over time leads to inefficient estimates since, each time, only a subset of the data is analyzed. These methods also presents a dilemma in terms of selection of the length of the window as short windows yield unreliable estimates while long windows imply coarse estimates and may also induce artificial autocorrelation.

Using before-and-after analysis $[9,25,38]$ to study parameter changes over time implies estimating different models before and after the event. The 'after' model is estimated using data from after the event under the assumption that this data represents the new and stabilized situation. A disadvantage of this approach is the loss in

\footnotetext{
${ }^{2}$ Such as the World Trade Organization (WTO), the World Bank (WB), and the International Monetary Fund (IMF).

${ }^{3}$ The studies that used surveys for understanding the impact of financial crisis on trade finance costs [30] are also susceptible to biases present in survey methods. First, survey responses have subjective components. If this subjectivity is common across the survey respondents, a strong bias will be present in their responses. For example, managers from the same country tend to exhibit common bias in their responses [8]. Second, survey responses are difficult to verify. Managers may over- or under-estimate their trade finance costs systematically, depending on the countries where their firms operate. Finally, survey research is often done in one cross-section of time, making it impossible to capture the variation over time.

${ }^{4}$ Methods like vector autoregression (VAR) often filter data to make it stationary [15, 17, 34].
} 
statistical efficiency as a result of ignoring effects present in part of the data. Further, this approach assumes that the underlying adjustment (due to events, such as the financial crisis) occurs instantaneously. However, in practice, it may take time for financial markets to adjust before it reaches a new equilibrium. This also serves to highlight the drawback of the approach in assuming time-invariant parameters for the 'before' model, as well as for the 'after' model.

Third, the effects of the drivers of trade finance cost may vary across countries [28], and we need to account for this heterogeneity. A well accepted way to incorporate heterogeneity is by using hierarchical models that estimate country-specific effects of the drivers of trade finance cost [40]. However, as hierarchical models are difficult to embed in time-series analysis [24], studies tend to aggregate data across cross-sections which leads to aggregation biases in the parameter estimates [14].

Nonstationarity, time-varying parameters and cross-sectional heterogeneity render measurement and modeling of factors that impact the dependent variable of interest - in our case, cost of trade finance-challenging in dynamic environments (such as a financial crisis). Therefore, we propose a dynamic hierarchical linear model (DHLM) that addresses all these three concerns and permits us to explain the variations in trade finance costs over several years, while also allowing us to detect any variation across countries, if present.

Our DHLM consists of three levels of equations. At the higher level, Observation Equation specifies, for each country in each year, the relationship between trade finance costs and a set of macroeconomic variables (e.g., inflation in the country). The coefficients of the predictors in the Observation Equation are allowed to vary across crosssection (i.e., countries) and over time. Next, in the Pooling Equation we specify the relationship between the country-specific time-varying coefficients (i.e., parameters) from the Observation Equation to a new set of parameters that vary over time, but are common across countries. Thus, the Pooling Equation enables us to capture the "average" time-varying effect of macroeconomic variables on trade finance cost. Finally, this "average" effect can vary over time and is likely to depend on its level in the previous period. The Evolution Equation, which is the lowest level of the DHLM, captures these potential changes in the "average" effects of the macroeconomic variables in a flexible way through a random walk.

We employ our DHLM to study how the effects of four macroeconomic variablesGDP growth, trade intensity, inflation, and stock market capitalization - on trade finance costs varied across 8 nations over a period of five years from 2006 to $2010 .^{5}$ Although the objective of our paper is to introduce a model that can address the different challenges outlined earlier, our model estimates provide several interesting insights. We find that the effect of macroeconomic indicators on the cost of trade finance varies over time and that most of this variation is present in the years preceding and succeeding the financial crisis. This is of interest to policymakers in deciding how long to implement interventions designed to ease the cost of trade finance. In addition, the trajectory of time-varying effects of GDP growth and inflation are consistent with

\footnotetext{
5 Stock market capitalization is scaled by GDP. Trade intensity is the ratio of a country's annual total trade and GDP. We use the terms "Trade Intensity" and "Trade/GDP" interchangeably.
} 
the "flight to quality" story [12]: during the crisis, cost of trade finance reduces in countries that have high GDP growth and low inflation. The time-varying effects of trade intensity is also consistent with our expectations, but the time-varying effect of market capitalization is counter-intuitive. Finally, we also note heterogeneity in the trajectory of the country-specific time-varying effects, primarily for the effects of stock market capitalization and trade intensity.

This research makes two contributions. First, we introduce a new model to the finance literature to study the evolution in the drivers of trade finance costs over time in dynamic environments such as a financial crisis, while also allowing the impact due to these drivers to be heterogeneous across countries. Our modeling approach addresses concerns related to nonstationarity, time-varying model parameters and cross-sectional heterogeneity that are endemic to time-series analysis of dynamic environments. Our model can be adopted to study evolution of various other variables such as financial services costs and global trade. Our model can also be extended to a more granular level to incorporate firm-level heterogeneity by using a second pooling equation. Doing this can pave the way to identify the characteristics of companies which may need assistance during a financial crisis. Thus, our research can remove subjectivity in extending benefits to the affected exporters and importers. Even large scale surveys may not be able to provide such granular implications to policy makers. Second, our research has substantive implications. Using a combination of data from Loan Pricing Corporation's Dealscan database and the World Bank, we complement the finance literature by empirically studying the evolution of the drivers of trade finance cost. We find that the impact of these drivers varies over time, with a large part of the variation present in the years preceding and succeeding the financial crisis. To the best of our knowledge, we are the first to study the time-varying impact of these macro-economic drivers on trade finance and this is of use to policy makers in deciding how long to extend benefits to parties affected by the crisis.

The paper proceeds as follows. In the first section we describe the DHLM. We provide the theoretical underpinnings necessary to estimate the model. Next we describe the data and variables used in the empirical analysis. In the fourth section we provide detailed discussion of the results. We conclude the paper with the discussion of the findings.

\section{Model Development}

We specify trade finance cost of a country as a function of country-specific macroeconomic variables and country-specific time-varying parameters using a DHLM. The DHLM has been used by previous studies in marketing and statistics [19, 26, 33, 35,39 ] to estimate time-varying parameters at the disaggregate level (e.g., at the level of a brand or store). A DHLM is a combination of Dynamic linear models (DLM) which estimates time-varying parameters at an aggregate level [5, 6], and a Hierarchical Bayesian (HB) model which estimates time-invariant parameters at the disaggregate level [31]. The DHLM and the HB model both have a hierarchical structure which permits us to pool information across different countries to arrive at overall aggregate-level inferences. Shrinking of the country-specific parameters to an 
"average" effect of the key variables across country has been used by other researchers to estimate country-specific tourism marketing elasticity [39] and to estimate store-level price elasticity [31].

We specify trade finance cost of a country as a function of country-level variables GDP growth, inflation, stock market capitalization and trade:

$$
\begin{aligned}
& \text { Trade_finance_cost }{ }_{i t}=\alpha_{i t}+\beta_{i t} G D P \_ \text {growth }_{i t}+\gamma_{i t} \text { Inflation }_{i t}+ \\
& \delta_{i t} \text { Stock_market_capitalization }_{i t}+\zeta_{i t} \text { Trade_intensity } \\
& i t
\end{aligned}
$$

where Trade_finance_cost $t_{i t}$ is the cost of trade finance of country $i$ at time $t$, $G D P \_$growth $_{i t}$ is the GDP growth of country $i$ at time $t$ Inflation $_{i t}$ is the Inflation of country $i$ at time $t$, Stock_market_capitalization ${ }_{i t}$ is the stock market capitalization of country $i$ at time $t$, Trade_intensity ${ }_{i t}$ is the intensity of trade of country $i$ at time $t, \alpha_{i t}$, $\beta_{i t}, \gamma_{i t}, \delta_{i t}$ and $\zeta_{i t}$ are country-specific time-varying coefficients and $u_{1}$ is the error term.

In order to specify the equations in a compact manner, we cast Eq. 1 as the observation equation of the DHLM. A DHLM also consists of a pooling equation and an evolution equation, and we specify these three equations below. ${ }^{6}$

We specify the observation equation as:

$$
y_{t}=\boldsymbol{F}_{\mathbf{1} t} \theta_{1 t}+v_{1 i t} ; \text { where } v_{1 i t} \sim N\left(0, \sigma_{v_{1}, i}^{2} \boldsymbol{I}_{\mathbf{1}}\right)
$$

An observation $y_{t}$ is defined as a vector that consists of country-specific trade finance cost at time $t$, whereas $\mathbf{F}_{\mathbf{1 t}}$ is a matrix that contains the country-specific macroeconomic variables at time $t$. The vector of parameters $\theta_{1 \mathrm{t}}$ contains all the countryspecific time-varying parameters defined in Eq. 1: $\alpha_{\mathrm{it}}, \beta_{\mathrm{it}}, \gamma_{\mathrm{it}}, \delta_{\mathrm{it}}$ and $\zeta_{\mathrm{it}}$.

The error term $\mathrm{v}_{1 \text { it }}$ is multivariate normal and is allowed to have a heteroskedastic variance $\sigma_{\mathrm{v}_{1}, \mathrm{i}}^{2}$, and $\mathbf{I}_{\mathbf{1}}$ an identity matrix of appropriate dimension. We specify $\mathrm{y}_{\mathrm{t}}, \mathrm{F}_{1 \mathrm{t}}$, and $\theta_{1 \mathrm{t}}$ similar to $[17,35]$.

We specify the pooling equation as:

$$
\theta_{1 t}=\boldsymbol{F}_{2 t} \theta_{2 t}+v_{2 t} ; \text { where } v_{2 t} \sim N\left(0, \sigma_{v_{2}}^{2} \boldsymbol{I}_{2}\right)
$$

We specify the country-specific time-varying parameters $\theta_{1 t}$ as a function of a new set of parameters $\theta_{2 t}$ that vary only in time. This hierarchical structure pools information across countries at every point in time, and thus $\theta_{2 t}$ represent the "average" timevarying effect. Hence, $\boldsymbol{F}_{2 t}$ is the matrix of 0's and 1's which allows us to specify the relationship between the average time-varying parameters $\theta_{2 t}$ and the country-specific time-varying parameters $\theta_{1 t}$. The error distribution $v_{2 t}$ is multivariate normal, and $\boldsymbol{I}_{\mathbf{2}}$ an identity matrix of appropriate dimension.

We specify how the average time-varying parameters, $\theta_{2 t}$, evolves over time. We follow the dynamic linear models (DLM) literature [43] and model the evolution of these parameters over time as a random walk.

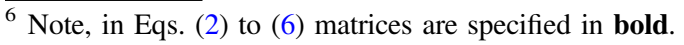


We specify the evolution equation as:

$$
\theta_{2 t}=\boldsymbol{G} \theta_{2, t-1}+w_{t} ; \text { where } w_{t} \sim N\left(0, \sigma_{w}^{2} \boldsymbol{I}_{3}\right)
$$

The random walk specification requires $\boldsymbol{G}$ to be an identity matrix and $w_{t}$ is a multivariate normal error, and $\boldsymbol{I}_{\mathbf{3}}$ an identity matrix of appropriate dimension.

\section{Estimation}

We compute the full joint posterior of the set of parameters $\left(\theta_{1 t}, \theta_{2 t}\right.$, and the variance parameters $\sigma_{v_{1}, i}^{2}, \sigma_{v_{2}}^{2}$, and $\sigma_{w}^{2}$ ) conditional on observed data. To generate the posteriors of the parameters we used the Gibbs sampler [16]. In the interest of space, we refer the reader to [26] for more details. As a robustness check, we estimate our DHLM on simulated data to check if our sampler is able to recover the parameters. The model we use to simulate the data in similar to the one [26] used for their simulation study. We find that our sampler performs well and recovers the parameters used to simulate the data. Space constraints prevent us from including further details.

\section{Data}

For the empirical tests, the data are derived from two sources. The information on trade finance costs is obtained from Loan Pricing Corporation's Dealscan database. The information on macroeconomic variables for the countries is obtained from the World Bank. We briefly describe the data sources.

\subsection{Dealscan}

Dealscan provides detailed information on loan contract terms including the spread above LIBOR, maturity, and covenants since 1986. The primary sources of data for Dealscan are attachments on SEC filings, reports from loan originators, and the financial press [41]. As it is one of the most comprehensive sources of syndicated loan data, prior literature has relied on it to a large extent [1, 3, 16, 23, 41].

The Dealscan data records, for each year, the loan deals a borrowing firm makes. In some instances, a borrower firm may make several loan deals in a year. To focus on trade finance, we limit the sample to only those loans where the purpose was identified by Dealscan as one of the following: Trade Finance, CP Backup, Pre-Export, and Ship Finance. Our trade finance costs are measured as the loan price for each loan facility, which equals the loan facility's at-issue yield spread over LIBOR (in basis points). Due to the limited number of observations, we don't differentiate between different types of loans. Instead, the trade finance costs are averaged across different types of loans such as revolver loans, term loans, and fixed-rate bonds. 


\subsection{The World Bank Data}

We use the World Bank data to get information on the economic and regulatory climate, and extent of development of the banking sector of the countries where the borrowing firms are headquartered. The economic and regulatory climate of a country is captured by GDP growth, inflation, stock market capitalization, and trade intensity.

Countries with high GDP growth are likely to face lower cost of trade finance, particularly during the financial crisis. As a high GDP growth is an indicator of the health of the economy, during the financial crisis lenders are likely to move their assets to these economies. Countries with higher inflation will likely have higher cost of trade finance as the rate of returns on the loans will incorporate the rate of inflation. We include stock market capitalization scaled by GDP as a proxy for the capital market development in the country. Countries with higher stock market capitalization are likely to have more developed financial markets. Therefore, the cost of trade finance in such markets is likely to be lower. Finally, we include total trade for the country scaled by the country's GDP as a measure of trade intensity. We expect that countries with a higher trade intensity will face a higher trade finance cost since a greater reliance on trade may make a country more risky during a crisis.

\subsection{Merging the Two Datasets}

As our objective is to study the phenomenon at the national level, we need to merge these two data sets. As our data from Dealscan contains trade finance costs at the firm level in a given year, we use the average of the trade finance costs at the level of a borrowing firm's home country to derive country-specific trade finance costs. This permits us to merge the data from Dealscan with macro-economic data from World Bank. Our interest is in modelling trade finance costs around the financial crisis of 2008-2009. Therefore, we use a 5-year time series starting in 2006 and ending in 2010. This gives us a reasonable window that contains pre-crisis, during the crisis, and postcrisis periods. While we would like to use a longer window, we are constrained by the number of years for which the data are available to us from Dealscan. After merging the two databases, our final sample consists of eight countries for which we have information on trade finance costs as well as macroeconomic indicators for all the five years. The eight countries are: Brazil, Ghana, Greece, Russia, Turkey, Ukraine, United Kingdom (UK), and the United States (USA).

\subsection{Descriptive Analysis}

We report the descriptive statistics for the sample in Table 1. Average trade finance costs are approximately 190 basis points above LIBOR. Mean GDP growth is just $2.57 \%$, reflecting the lower growth during the financial crisis. Although average inflation is at $10.53 \%$, we calculated the median inflation to be a moderate $6.55 \%$. On average stock market capitalization/GDP ratio is around $63 \%$ while trade/GDP ratio is around $54 \%$. More detailed summary statistics for the trade finance costs are depicted in Fig. 1. 
Table 1. Descriptive statistics.

\begin{tabular}{l|l|r|r}
\hline Variables & $\mathrm{N}$ & \multicolumn{1}{c}{ Mean } & St. Deviation \\
\hline Trade finance cost above LIBOR (basis points) & 40 & 189.43 & 155.50 \\
\hline GDP growth \% & 40 & 2.57 & 5.16 \\
\hline Inflation \% & 40 & 10.53 & 13.32 \\
\hline Stock market cap/GDP & 40 & 62.96 & 43.65 \\
\hline Trade/GDP & 40 & 54.11 & 22.28 \\
\hline
\end{tabular}

Figure 1 captures the variation in trade finance cost over time and across 8 countries. We find countries experience a large increase in trade finance costs from 2008 to 2009. Also, except for Greece, these costs came down in 2010 from their peak in 2009. This suggests that the crisis impacted trade finance costs uniformly in our sample. We also see heterogeneity across countries in the manner in which these costs evolve over time.

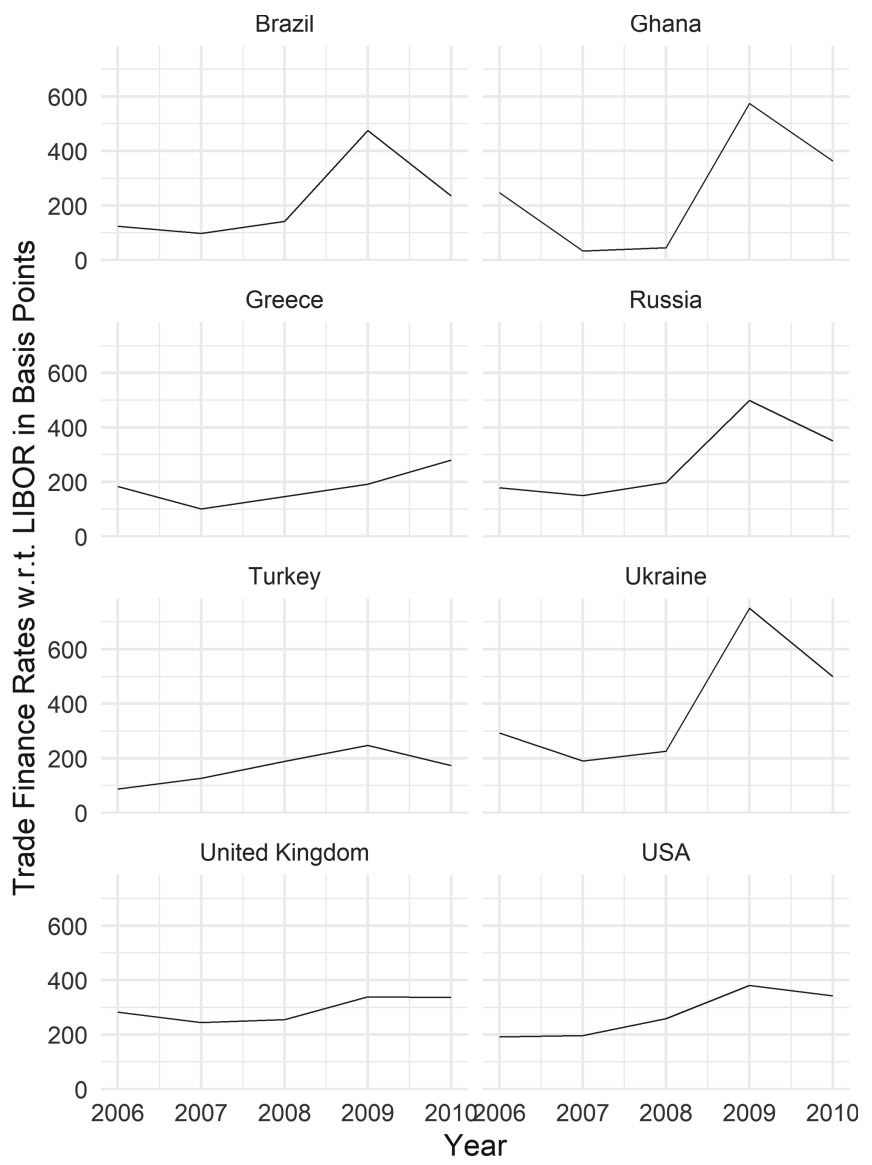

Fig. 1. Trade finance costs 
We also tested for multicollinearity among the independent variables, GDP growth, Inflation, Stock market capitalization and Trade intensity. We specified a panel data regression model (i.e., without time-varying parameters) and calculated the Variance Inflation Factors (VIFs). The VIFs we get for GDP growth, Inflation, Stock market capitalization and Trade intensity are $1.13,1.15,1.42$ and 1.36 respectively. As the VIFs are less than 10, we can conclude that multicollinearity is not a concern [44].

\section{Results}

In this section, we present the main results based on our DHLM, and subsequently compare our model to the benchmark HB model in which the parameters do not vary over time.

\subsection{Main Findings Based on the DHLM}

We estimate our model using the Gibbs sampler [18]. We use 200,000 iterations and use the last 20,000 iterations for computing the posterior, while keeping every tenth draw. We verified the convergence of our Gibbs sampler by using standard diagnostics: (1) We plotted the autocorrelation plot of the parameters and see that the autocorrelation goes to zero [40] and (2) we plot and inspect the posterior draws of our model parameters and find that they resemble a "fat, hairy caterpillar" that does not bend [29].

We first present the estimates for the Pooling Equation $\left(\theta_{2}\right)$ which are summarized in Fig. 2. These estimates represents the "average" effect across countries of the four macroeconomic variables, GDP growth, Inflation, Stock market capitalization and the Trade/GDP ratio. In Fig. 2, each of the four panels depict the "average" effect, over time, of the macro-economic variables on the cost of trade finance. The dotted lines depict the $95 \%$ confidence interval (CI). We discuss these "average" time-varying effects in the subsequent paragraphs.

We see that for all four macro-economic variables, the effects vary over time. In addition, a large part of the variations occur between 2007 to 2009, the 2 year span during which the financial crisis happened. Our estimates will interest policy makers as it implies that interventions to alleviate the impact of the crisis should start before its onset and should continue for some time after it has blown over.

We find that GDP Growth has a negative effect on Trade finance costs and this effect becomes more negative over time, especially during the years 2006 to 2009. Our result implies that countries with high GDP Growth faced monotonically decreasing cost of trade finance in the years before and during the financial crisis, and can be explained by the "flight to quality" hypothesis advanced in the finance literature [12].

Inflation has a positive effect on the cost of trade finance and this effect become more positive over time, especially during 2007 to 2009 which are the year preceding the crisis and the year of the crisis. Our result implies that countries with high inflation faced monotonically increasing costs of trade finance from 2007 to 2009 and is also consistent with the "flight to quality" theory.

Stock Market Capitalization has a positive effect on the cost of trade finance. This effect seems somewhat counterintuitive as we used Stock Market Capitalization as a 


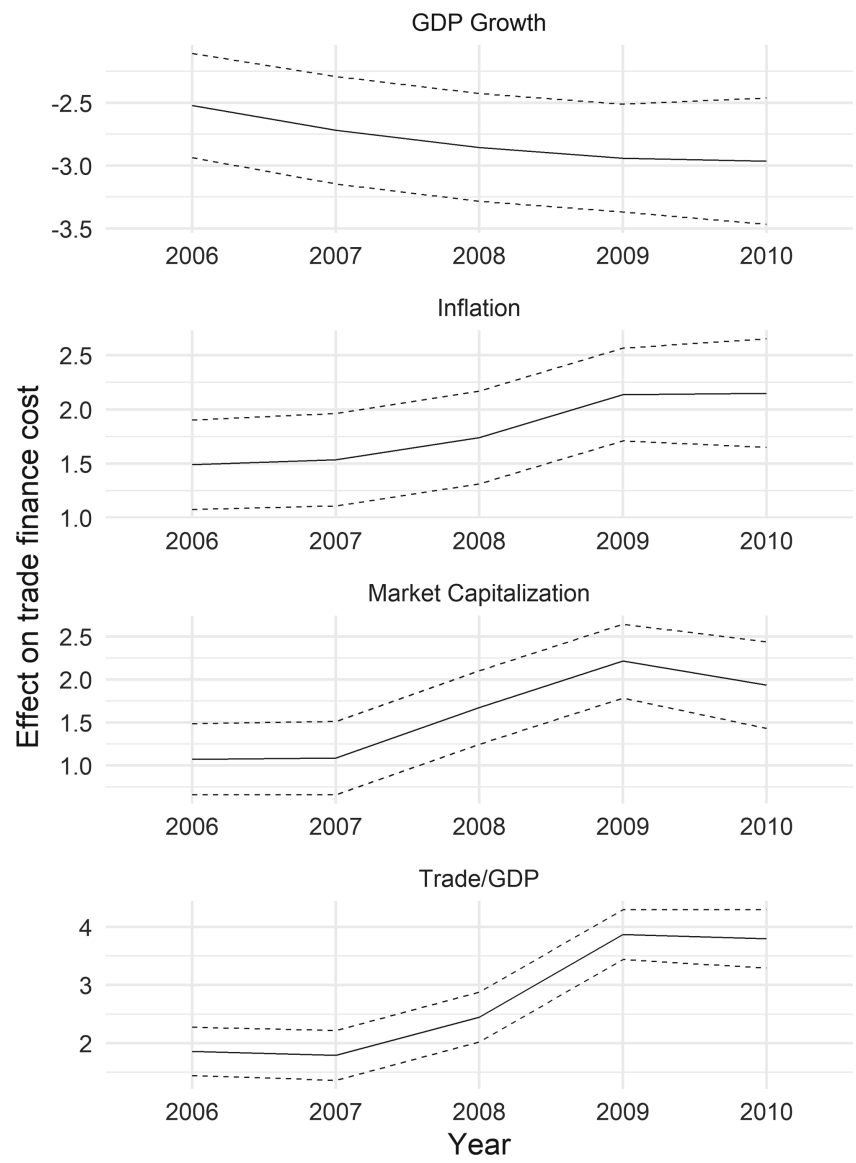

Fig. 2. Estimates of Pooling Equation $\left(\theta_{2}\right)$. Notes: Solid line depicts the estimate. Dotted lines indicate the $95 \%$ confidence interval.

proxy for development of financial markets and one would expect that during the financial crisis trade finance costs would decrease as financial markets became more developed.

We note that the Trade/GDP ratio has a positive effect on the cost of trade finance, and this effect becomes more positive between the years 2007 to 2009, similar to the pattern we noticed for the effects of inflation. Since this variable measures the intensity of trade of a country, our results indicate that, during the financial crisis, a greater reliance on trade leads to higher costs of trade finance. This is expected since higher reliance on trade may make a country more risky in a financial crisis. Countries with higher trade intensity are also exposed to higher counterparty risks. 
Our model can also estimate country-specific time-varying parameters presented in the Observation Equation $\left(\theta_{1}\right)$. These estimates underscore the advantage of using a model such as ours, since with only 40 observations of our dependent variable, we are able to estimate 200 estimates which are country-specific and time-varying. ${ }^{7}$ We note some heterogeneity in the country-specific trajectory of the effects of Stock Market Capitalization and Trade Intensity. For example, we see that for some countries such as Ghana, Russia and Greece, the effect of trade/GDP ratio on the cost of trade finance witnesses a steeper increase compared to other countries such as USA and Ukraine in 2008 to 2009, the year of the crisis; we are unable to present these results due to space constraints. However, these findings offer directions for future research.

\subsection{Model Comparison}

To assess model fit, we compare the forecasting accuracy of our proposed model to the benchmark Hierarchical Bayesian (HB) model which has time-invariant parameters. We specify the HB model as follows:

$$
\begin{gathered}
Y=X_{1} \mu_{1}+\varepsilon_{1} ; \text { where } \varepsilon_{1} \sim N\left(0, V_{\varepsilon_{1}}\right) \text { and } \\
\mu_{1}=X_{2} \mu_{2}+\varepsilon_{2} ; \text { where } \varepsilon_{2} \sim N\left(0, V_{\varepsilon_{2}}\right)
\end{gathered}
$$

The above specification is similar to the DHLM with the major difference being that the parameters now do not vary over time. The dependent variables $(Y)$ and independent variables $\left(\boldsymbol{X}_{1}\right)$ are the same as those in the proposed model, while $\boldsymbol{X}_{\mathbf{2}}$ is a matrix that adjusts the size of $\mu_{1}$ to that of $\mu_{2}$.

We compare the model fit by computing the out-of-sample one-step-ahead forecast of our proposed model and the benchmark model. We calculate the mean absolute percentage error (MAPE), which is a standard fit statistic for model comparison [17, 35]. We find that the MAPE of our proposed model is 21.11, while that of the benchmark HB model is 42.68. Thus our proposed model forecasts more accurately than the benchmark HB model.

\section{Discussion and Conclusion}

In this research, we attempt to shed light on the following question: How can we develop a model that would permit us to examine variations in trade finance costs over time in dynamic environments (such as a financial crisis), while also accounting for possible variations across countries? We addressed this question by proposing a DHLM model that can cope with the three challenges present when modeling data from dynamic environments: nonstationarity, changes in parameters over time and

\footnotetext{
${ }^{7}$ We have 200 estimates since we have 8 countries and 5 time periods, and 5 independent variables (including the intercept). This large number of parameters can be estimated due to our model structure: (i) a first order Markov process relates the parameter at time $t$ to the parameter at $t-1$, and the parameters across countries at a time $t$ are tied together using a Hierarchical Bayesian structure.
} 
cross-sectional heterogeneity. Our model estimates detect variation over time of the macroeconomic drivers o trade finance, which are of interest to policy makers in deciding when and for how long to schedule interventions to alleviate the impact of a financial crisis. Further, the trajectory of the time-varying effects of the macroeconomic indicators are in line with our expectations. We also note some degree of countryspecific heterogeneity in the manner in which these drivers evolve over time, and a detailed scrutiny of these findings may prove fertile ground for future research.

The DHLM can be easily scaled up thereby allowing us to extend our analysis. First, we can add another level in the model hierarchy by specifying a second pooling equation. This would permit us to study the problem at the firm level since evidence suggests that - during the crisis - firms from developing countries and financially vulnerable sectors faced higher trade finance costs $[13,30]$, and one can use recent NLP approaches [37] to gather firm information across different data sources. Second, more macroeconomic variables can be added in the observation equation. In addition, our model can be used to study other contexts that face dynamic environments such as financial services costs and global trade.

The suitability of our model for dynamic environments also implies that it can also be used to study the impact of the recent coronavirus (COVID-19) on financial activities, since reports from the European Central Bank have suggested that the virus can lead to economic uncertainty. In many ways, the way the virus impacts the economy is similar to that of the financial crisis: There is no fixed date on which the interventions starts and ends - unlike, for example, the imposition of a new state tax and its impact may vary over time as the virus as well as people's reaction to it gains in strength and then wanes and it would be interesting to model these time-varying effects to see how they evolve over time.

\section{References}

1. Acharya, V.V., Almeida, H., Campello, M.: Aggregate risk and the choice between cash and lines of credit: aggregate risk and the choice between cash and lines of credit. J. Finan. 68(5), 2059-2116 (2013)

2. Ahn, J.: A theory of domestic and international trade finance. In: IMF Working Papers, pp. 1-35 (2011)

3. Almeida, H., Campello, M., Hackbarth, D.: Liquidity mergers. J. Finan. Econ. 102(3), 526558 (2011)

4. Amiti, M., Weinstein, D.E.: Exports and financial shocks. Q. J. Econ. 126(4), 1841-1877 (2011)

5. Ataman, M.B., Van Heerde, H.J., Mela, Carl F.: The long-term effect of marketing strategy on brand sales. J. Mark. Res. 47(5), 866-882 (2010)

6. Ataman, M.B., Mela, C.F., van Heerde, Harald J.: Building brands. Mark. Sci. 27(6), 10361054 (2008)

7. Auboin, M.: Boosting trade finance in developing countries: what link with the WTO? Working paper, SSRN eLibrary (2007)

8. Baumgartner, Hans, Steenkamp, J.-B.E.M.: Response styles in marketing research: a crossnational investigation. J. Mark. Res. 38(2), 143-156 (2001) 
9. Berger, A.N., Turk-Ariss, R.: Do depositors discipline banks and did government actions during the recent crisis reduce this discipline? An international perspective. J. Finan. Serv. Res. 48(2), 103-126 (2015). https://doi.org/10.1007/s10693-014-0205-7

10. Beck, T., Demirgüç-Kunt, A., Levine, R.: Financial institutions and markets across countries and over time-data and analysis. In: World Bank Policy Research Working Paper Series (2009)

11. Bronnenberg, B.J., Mahajan, V., Vanhonacker, W.R.: The emergence of market structure in new repeat-purchase categories: the interplay of market share and retailer distribution. J. Mark. Res. 37(1), 16-31 (2000)

12. Caballero, R.J., Krishnamurthy, A.: International and domestic collateral constraints in a model of emerging market crises. J. Monet. Econ. 48(3), 513-548 (2001)

13. Chor, D., Manova, K.: Off the cliff and back? Credit conditions and international trade during the global financial crisis. J. Int. Econ. 87(1), 117-133 (2012)

14. Christen, M., Gupta, S., Porter, J.C., Staelin, R., Wittink, D.R.: Using market-level data to understand promotion effects in a nonlinear model. J. Mark. Res. 34, 322-334 (1997)

15. Colicev, A., Malshe, A., Pauwels, K., O'Connor, P.: Improving consumer mindset metrics and shareholder value through social media: the different roles of owned and earned media. J. Mark. 82(1), 37-56 (2018)

16. Dahiya, S., John, K., Puri, M., Ramírez, G.: Debtor-in-possession financing and bankruptcy resolution: empirical evidence. J. Finan. Econ. 69(1), 259-80 (2003)

17. Dekimpe, M.G., Hanssens, D.M.: The persistence of marketing effects on sales. Mark. Sci. 14(1), 1-21 (1995)

18. Gelfand, A.E., Smith, A.F.M.: Sample-based approaches to calculating marginal densities. J. Am. Stat. Assoc. 85, 398-409 (1990)

19. Gopinath, S., Thomas, J.S., Krishnamurthi, L.: Investigating the relationship between the content of online word of mouth, advertising, and brand performance. Mark. Sci. 33(2), 241258 (2014)

20. Greene, W.H.: Econometric Analysis 7th Edition International edition (2003)

21. Haddad, M., Ann H., Hausman, C.: Decomposing the great trade collapse: products, prices, and quantities in the 2008-2009 crisis. National Bureau of Economic Research (2010)

22. Hamilton, J.D.: Time Series Analysis. Princeton University Press, Princeton (1994)

23. Haselmann, R., Wachtel, P.: Foreign banks in syndicated loan markets. J. Bank. Finan. 35 (10), 2679-2689 (2011)

24. Horváth, C., Wieringa, J.E.: Combining time series and cross sectional data for the analysis of dynamic marketing systems. Working paper, University of Groningen (2003)

25. Kadiyali, V., Vilcassim, N., Chintagunta, P.: Product line extensions and competitive market interactions: an empirical analysis. J. Econ. 89(1-2), 339-363 (1998)

26. Landim, F., Gamerman, D.: Dynamic hierarchical models: an extension to matrix-variate observations. Comput. Stat. Data Anal. 35(1), 11-42 (2000)

27. Levchenko, A.A., Lewis, L.T., Tesar, L.L.: The collapse of international trade during the 2008-09 crisis. In search of the smoking gun. IMF Econ. Rev. 58(2), 214-253 (2010). https://doi.org/10.1057/imfer.2010.11

28. Levine, R., Loayza, N., Beck, T.: Financial intermediation and growth: Causality and causes. J. Monet. Econ. 46, 31-77 (2000)

29. Lunn, D., Jackson, C., Best, N., Spiegelhalter, D., Thomas, A.: The BUGS Book: A Practical Introduction to Bayesian Analysis. Chapman and Hall/CRC, Boco Raton (2012)

30. Malouche, M.: Trade and trade finance developments in 14 developing countries post September 2008-A World Bank Survey. In: World Bank Policy Research Working Paper Series (2009) 
31. Montgomery, A.L.: Creating micro-marketing pricing strategies using supermarket scanner data. Mark. Sci. 16(4), 315-337 (1997)

32. Mela, C.F., Gupta, S., Lehmann, D.R.: The long-term impact of promotion and advertising on consumer brand choice. J. Mark. Res. 34, 248-261 (1997)

33. Mullick, S., Glady, N., Gelper, S.: Price elasticity variations across locations, time and customer segments: an application to the self-storage industry. Working paper, Available at SSRN 3285521(2020)

34. Mullick, S., Raassens, N., Hans, H., Nijssen, E.J.: Reducing food waste through digital platforms: a quantification of cross-side network effects. Working paper (2020). https:// research.tue.nl/en/publications/defining-the-leader-and-the-follower-in-a-two-sided-marketproble

35. Neelamegham, R., Chintagunta, P.K.: Modeling and forecasting the sales of technology products. Quant. Mark. Econ. 2(3), 195-232 (2004). https://doi.org/10.1023/B:QMEC. 0000037077.02026.50

36. Nelson, J.P.: Consumer bankruptcies and the bankruptcy reform act: a time-series intervention analysis, 1960-1997. J. Finan. Serv. Res. 17(2), 181-200 (2000). https://doi. org/10.1023/A:1008166614928

37. Paalman, J., Mullick, S., Zervanou, K., Zhang, Y.: Term based semantic clusters for very short text classification. In: Proceedings of the International Conference Recent Advances in Natural Language Processing, pp. 878-887 (2019). https://doi.org/10.26615/978-954-452056-4_102

38. Pauwels, K., Srinivasan, S.: Who benefits from store brand entry? Mark. Sci. 23(3), 364-390 (2004)

39. Peers, Y., van Heerde, H.J., Dekimpe, M.G.: Marketing budget allocation across countries: the role of international business cycles. Mark. Sci. 36(5), 792-809 (2017)

40. Rossi, P.E., Allenby, G.M., McCulloch, R.: Bayesian Statistics and Marketing. Wiley, Hoboken (2012)

41. Sufi, A.: Information asymmetry and financing arrangements: evidence from syndicated loans. J. Finan. 62(2), 629-668 (2007)

42. Heerde, V., Harald, J., Mela, C., Manchanda, P.: The dynamic effect of innovation on market structure. J. Mark. Res. 41(2), 166-183 (2004)

43. West, M., Harrison, J.: Bayesian Forecasting and Dynamic Models. Springer, New York (1997). https://doi.org/10.1007/b98971

44. Yoder, B.J., Pettigrew-Crosby, R.E.: Predicting nitrogen and chlorophyll content and concentrations from reflectance spectra (400-2500 nm) at leaf and canopy scales. Remote Sens. Environ. 53(3), 199-211 (1995) 